\title{
MONITORIZAÇÃO HEMODINÂMICA INVASIVA
}

\author{
THERMODILUITION CARDIAC OUTPUT MEASUREMENTS
}

\author{
Gerson Alves Pereira Júnior ${ }^{1}$, Flávio Marson ${ }^{1}$, Fátima M. Ostini ${ }^{1}$, Paulo Antoniazzi ${ }^{1}$, \\ Mabel Duarte A. Gomide ${ }^{2}$, Anibal Basile-Filho ${ }^{3}$
}

\begin{abstract}
${ }^{1}$ Médicos Intensivistas, ${ }^{2}$ Médica Residente - Disciplina de Terapia Intensiva, ${ }^{3}$ Docente e Chefe da Disciplina de Terapia Intensiva. Departamento de Cirurgia, Ortopedia e Traumatologia da Faculdade de Medicina de Rribeirão Preto - Universidade SP.

CORRESPONDÊNCIA: Anibal Basile Filho - Disciplina de Terapia Intensiva, Departamento de Cirurgia, Ortopedia e Traumatologia da FMRP-USP - Hospital das Clínicas Campus Universitário - 14048-900 - Ribeirão Preto - SP - Fone: (016) 633-0836 ou $602-2593$
\end{abstract}

PEREIRA Jr. GA et al. Monitorização hemodinâmica invasiva. Medicina, Ribeirão Preto, 31: 380-399, jul./set. 1998.

RESUMO: O objetivo deste artigo é revisar todos os aspectos envolvidos na monitorização hemodinâmica invasiva do uso do cateter de Swan-Ganz. Esta prática, à beira do leito, será analisada em termos da sua indicação, da sua técnica de introdução, da verificação do seu posicionamento - através do acompanhamento das ondas de pressão e de encunhamento, e da radiografia do tórax - e do procedimento para as medidas hemodinâmicas, discutindo-se os principais fatores de erros que podem ser cometidos e as possíveis complicações do uso desse procedimento.

UNITERMOS: Artéria Pulmonar. Cateterismo de Swan-Ganz. Cateterismo. Hemodinâmica. Pressão Propulsora Pulmonar. Termodiluição. Débito Cárdiaco.

\section{INTRODUÇÃO}

A utilização clínica do cateter de Swan-Ganz (cateterização da artéria pulmonar, dirigida pelo fluxo) iniciou-se nos primeiros anos da década de $1970^{(1)}$ e difundiu-se rapidamente devido a sua praticidade $\mathrm{e}$ eficácia, na medida das pressões hemodinâmicas e na determinação do débito cardíaco pelo uso do computador, guiando a administração de líquidos intravenosos, inotrópicos e agentes redutores da pós-carga ${ }^{(2)}$. $\mathrm{O}$ cateter pode ser inserido em cirurgias, em salas de cateterização hemodinâmica ou à beira do leito, usualmente sem fluoroscopia, por monitorização das pressões e observação das formas de ondas durante a inserção. O cateter é radiopaco e a fluoroscopia e/ ou a radiografia simples pode ser usada para guiar ou verificar a sua posição ${ }^{(2)}$.

O princípio da termodiluição, utilizado no cálculo do débito cardíaco, é uma extensão da diluição de indicador (no caso, um indicador térmico), na qual uma quantidade conhecida de indicador (ex.: frio) é injetada em um local especificado "corrente acima" (ex.: átrio direito) e o resultante efeito dilucional do indicador, ao misturar-se com sangue, numa localização "corrente abaixo" (ex.: termistor na artéria pulmonar), é medido, gerando uma curva de diferencial de temperatura, e a área abaixo desta curva é integrada. Dessa maneira, o débito cardíaco é calculado, empregando-se a fórmula de Stewart-Hamilton de diluição do indicador $^{(3)}$.

O crescimento dos custos na área da saúde e o contínuo progresso tecnológico têm se tornado uma preocupação em todo o mundo, sendo colocada em dúvida a real eficácia destes serviços prestados em relação aos custos e resultados finais. Embora se reconheça que o uso extensivo do cateter de SwanGanz tenha trazido importantes subsídios para o entendimento da fisiopatologia e para uma racionaliza- 
ção terapêutica em diversos distúrbios hemodinâmicos, observados no paciente crítico, não há, após mais de vinte e cinco (25) anos de uso da técnica, dados conclusivos que indiquem um impacto positivo no que se refere à diminuição da mortalidade na $\mathrm{UTI}^{(4)}$.

O objetivo deste artigo é apresentar uma revisão crítica sobre o uso do cateter de Swan-Ganz, analisando suas indicações, técnica de introdução e correta localização do cateter, bem como enumerar os vários fatores que podem levar ao erro no cálculo das variáveis hemodinâmicas.

\section{TIPOS DE CATETER}

$O$ cateter existe nos tamanhos neonatal (3 French), pediátrico (5 French) e adulto (7 French). Os cateteres adultos existem em dois comprimentos: 85 e $110 \mathrm{~cm}$. O corpo do cateter contém quatro (4) vias, além do balão em sua extremidade distal ${ }^{(2)}$. A função de cada via vem a seguir.

a) Via proximal (azul): seu orifício situa-se a $29 \mathrm{~cm}$ da extremidade distal. Permite a injeção de líquidos para as medidas hemodinâmicas e é utilizado também para a medida da pressão venosa, central (PVC) e colheita de exames de sangue.

b) Via distal (amarela): seu orifício situa-se na ponta do cateter, permitindo a medida das pressões nas câmaras cardíacas, direitas, pressão arterial pulmonar e pressão capilar, pulmonar, durante a inserção, além da colheita de amostra do sangue venoso, misto, na artéria pulmonar.

c) Via do balão (vermelha): auxilia na migração do cateter pela flutuação dirigida pelo fluxo, permitindo o encunhamento do cateter e a medida da pressão capilar pulmonar, quando inflado em um ramo da artéria pulmonar. Tem o volume de 1,5 ml.

d) Termistor: consiste em dois finos fios isolados, estendendo-se pelo comprimento do cateter e terminando em um termistor embutido na parede do cateter, situado na superfície do cateter $4 \mathrm{~cm}$ proximais à extremidade distal, que mede a temperatura sanguínea na artéria pulmonar, continuamente, sendo que, através da termodiluição, realiza as medidas hemodinâmicas com o uso de um computador.

O cateter possui marcas que indicam a profundidade de inserção, onde as linhas negras finas indicam $10 \mathrm{~cm}$ e as linhas negras largas indicam $50 \mathrm{~cm}$.

Atualmente, temos, disponíveis no mercado, cateteres com módulos que permitem a medida contínua da oximetria venosa, central, fração de ejeção ventricular direita e débito cardíaco, sendo, substancialmente, mais caros do que os cateteres padrão. Não há, no momento, pesquisa que mostre a efetividade ou a falta de efetividade destes cateteres nos vários subgrupos de pacientes críticos ${ }^{(5)}$.

\section{INDICAÇÕES}

Sem as informações fornecidas pelos cálculos hemodinâmicos, através do uso do cateter de SwanGanz, a capacidade de avaliar eficazmente o débito cardíaco e as pressões de enchimento ventricular esquerdo, no paciente crítico, é pobre, apesar das informações obtidas pela anamnese e por um exame físico cuidadoso $^{(5,6)}$.

O cateter de Swan-Ganz é um instrumento de monitorização diagnóstica e não uma modalidade terapêutica. A alteração terapêutica proporcionada, como adequação da reposição volêmica e melhor titulação da dose das drogas vasoativas, pode melhorar o prognóstico do paciente e não o uso isolado do cateter de Swan-Ganz ${ }^{(4,5)}$. Se o cateter é usado e a informação é ignorada ou mal interpretada, o paciente submeteu-se a um risco potencial, desnecessário pelo procedimento, sem qualquer esperança de benefícios. Do mesmo modo, se a informação é incorretamente obtida pelo uso do cateter, uma estratégia terapêutica imprópria pode ser empregada ${ }^{(5)}$. Este assunto não tem sido enfocado de maneira mais consistente, porém os trabalhos questionando acerca dos conhecimentos elementares sobre o cateter de SwanGanz, tanto por parte dos médicos, quanto da enfermagem, realizados em centros avançados do mundo, na Europa e nos Estados Unidos, mostram resultados alarmantes, a ponto de $47 \%$ dos médicos americanos e 54\% dos europeus não identificarem corretamente os valores de pressão capilar pulmonar, mesmo com um claro traçado ${ }^{(7)}$. Tem-se notado que o cateter é usado mais por costume e porque a técnica encontrase disponível do que realmente pelos benefícios que possa trazer ao paciente ${ }^{(4,5)}$.

Sendo assim, foi desenvolvida na nossa Unidade de Terapia Intensiva da Unidade de Emergência do Hospital das Clínicas de Ribeirão Preto (USP), uma técnica informatizada para a interpretação dos resultados obtidos através do cateter de Swan-Ganz (ver próximo tópico do Simpósio), de fácil disponibilidade para uso rotineiro.

A incerteza clínica sobre o diagnóstico do estado hemodinâmico atual e a presença de estados he- 
modinâmicos rapidamente mutáveis são as condições nas quais a cateterização da artéria pulmonar pode ser útil, após esgotar as possibilidades de as informações necessárias poderem ser obtidas por métodos não invasivos ${ }^{(3,4,8,9)}$.

Atualmente, não há ainda um consenso dentre as indicações de uso do cateter de Swan-Ganz, visto que há uma enorme quantidade de trabalhos publicados a esse respeito, porém com metodologia duvidosa, permitindo controvérsias a respeito das suas verdadeiras indicações. Alguns autores, inclusive, chegaram a publicar resultados de trabalhos, mostrando que o uso do cateter de Swan-Ganz aumenta a mortalidade $^{(10,11)}$. Tal confusão tem gerado a necessidade de uma moratória para a utilização do cateter de Swan-

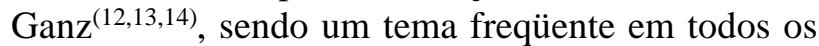
debates, na área de Terapia Intensiva, no Brasil e no exterior. Grande esforço tem ocorrido entre "experts" no assunto para a obtenção de um consenso ${ }^{(5)}$.

As principais indicações são as seguintes ${ }^{(2,3,4,5,6)}$ : a) Necessidade de avaliação das variáveis hemodinâmicas através das medidas seriadas e da monitorização da pressão atrial direita, pressão arterial pulmonar e/ou pressão capilar pulmonar, nos casos abaixo relacionados.

a.1) Insuficiência cardíaca aguda (ex.: infarto agudo do miocárdio, complicado com hipotensão progressiva ou choque cardiogênico).

a.2) Complicações mecânicas do infarto agudo do miocárdio (Diferenciação da ruptura do septo interventricular da regurgitação mitral por ruptura de músculo papilar ou tamponamento cardíaco). Há técnicas menos invasivas, tal como a ecocardiografia, para rápido auxílio diagnóstico.

a.3) Infarto do ventrículo direito. $\mathrm{O}$ cateter de Swan-Ganz ajuda a guiar a expansão volêmica e o suporte farmacológico dos pacientes hipotensos com infarto do ventrículo direito.

a.4) Insuficiência cardíaca congestiva refratária. Os sinais clínicos e radiológicos correlacionam-se pobremente com a gravidade da insuficiência cardíaca. O cateter de Swan-Ganz pode ser útil não apenas para otimizar o balanço hídrico, mas, também, para definir os pacientes nos quais a terapia não pode ser tolerada ou é ineficiente, que são os casos em que pode estar indicado o uso do balão intra-aórtico. Modalidades diagnósticas menos invasivas como a ecocardiografia também podem guiar a terapêutica nestes casos. a.5) Hipertensão pulmonar. O cateter de SwanGanz é indicado para diagnóstico e para guiar a terapia vasodilatadora nestes pacientes.

a.6) Choque circulatório ou instabilidade hemodinâmica, que não respondou a expansão volêmica nem ao uso de drogas vasoativas. A avaliação clínica do estado hemodinâmico não é confiável nestes pacientes.

a.7) Situações circulatórias complexas (ex.: reposição volêmica, no grande queimado).

a.8) Emergências médicas, como as abaixo indicadas.

- Síndrome da Angústia Respiratória Aguda (SARA). O cateter de Swan-Ganz auxilia nestes casos, principalmente nos casos de hipotensão, com evidência clínica de má perfusão tecidual ou nos pacientes estáveis hemodinamicamente, porém refratários ao uso de diuréticos;

- Sepse por bactérias gram-negativas. O cateter de Swan-Ganz é útil nos pacientes que não respondem à reposição volêmica e ao uso de aminas simpatomiméticas, onde a PVC não é fidedigna, sendo elevada pela disfunção ventricular direita $^{(15)}$;

- intoxicação por drogas;

- insuficiência renal aguda;

- pancreatite necroemorrágica.

a.9) Pacientes de alto risco intra e pós-operatório:

- história de prévia doença cardíaca ou pulmonar;

- cirurgias de grande porte, principalmente cardíacas e aórticas, em pacientes com disfunção ventricular, esquerda, importante;

a.10) Pacientes obstétricas de alto risco:

- cardiopatas (ex.: estenose mitral);

- doença hipertensiva específica da gestação (pré-eclâmpsia), o uso do cateter de SwanGanz está indicado nas pacientes com pré-eclâmpsia severa, associada com oligúria, não responsiva a ressuscitação volêmica, presença de edema pulmonar ou hipertensão resistente à terapia;

- descolamento prematuro de placenta.

b) Determinação do débito cardíaco pelo método de termodiluição.

c) Colheita de sangue venoso misto e infusão de soluções.

As contra-indicações ${ }^{(2)}$ estão relacionadas ao: a) Uso de heparina para a manutenção da permeabilidade do cateter em pacientes com conhecida hipersensibilidade à heparina. 
b) pacientes com sepse recorrente ou estados de hipercoagulabilidade, onde a presença do cateter serve como ponto para a manutenção da sepse ou formação de trombos.

c) pacientes com alterações do ritmo cardíaco, sendo obrigatória a monitorização eletrocardiográfica, principalmente nos casos de:

c.1) bloqueio completo do ramo esquerdo, onde há risco de bloqueio atrioventricular, total;

c.2) Síndrome de Wolff-Parkinson-White (feixe acessório, anômalo) e Malformação de Ebstein (atrialização do ventrículo direito), onde há risco de taquiarritmias.

\section{PROCEDIMENTO}

\subsection{Material a ser utilizado}

- Cateter de Swan-Ganz (termodiluição).

- "Kit" introdutor, que é composto de material para punção percutânea (antisséptico, anestésico local, campo cirúrgico estéril, gazes, seringas, agulhas para punção profunda, bisturi, fio cirúrgico, um fio guia, o introdutor, o cateter com sua bainha e a "camisinha" protetora que mantém o cateter estéril no seu interior, para manipulações posteriores).

- Transdutores de pressão e amplificadores (domes).

- Monitor com ECG contínuo e canal de pressão invasiva.

- Dois (2) equipos conectando as vias proxi- zado e deve ser preenchido com salina. É melhor fazer isto antes de conectar o sistema de conexão ao transdutor, pois todas as partes podem ser vistas e manipuladas mais facilmente. Para minimizar a formação de bolhas, usar a solução de salina à temperatura ambiente e encher o sistema lentamente ${ }^{(16)}$. Quando este procedimento é realizado corretamente, o sistema de conexão está montado, repleto de solução salina, livre de bolhas e sem distensão da membrana do "dome".

A solução contendo heparina é pressurizada em uma bolsa a $300 \mathrm{mmHg}$, o que permite uma baixa e contínua infusão para evitar a formação de trombos e manter o lúmen aberto.

Colocar salina na face espelhada do transdutor, o necessário para cobrir todo o centro de sua superfície, deixando-o numa inclinação tal que o líquido não escorra. Conectar o "dome" ao transdutor, rodando-o $1 / 6$ de sua volta no sentido horário. O "dome" não deve estar pressurizado quando isto é feito ${ }^{(16)}$. Na interface entre o "dome" e o transdutor não deve haver excesso de líquido nem bolhas. Se houver bolhas, remover o "dome", secar o transdutor e repetir o procedimento (ver Figura 1).

Para encher o sistema de conexão com solução salina, inicialmente, feche a "torneirinha" para o paciente e abra a "torneirinha" do "dome" e encha o sistema lentamente. Após estar repleto, deve-se zerar o sistema, mantendo-o aberto para o ambiente e calibrando o monitor. Agora, abrir a "torneirinha" para o paciente e fechar para o ambiente, enchendo o res-

mal e distal do cateter ao transdutor de pressão.

- Quatro (4) "torneiras" (stopcock) de três (3) vias.

- Solução estéril, contendo heparina (SF $0,9 \%-500 \mathrm{ml}+0,5$ $\mathrm{ml}$ de heparina) em bolsa pressurizadora (mantendo a pressão de $300 \mathrm{mmHg}$ constante) e sistema de lavagem ("flush device").

\subsection{Montagem do sistema}

Ligar o monitor de pressão e conectá-lo ao transdutor, selecionando a altura apropriada do adaptador que sustentará o transdutor, na linha média axilar.

O sistema de conexões (dome, equipos interconectores e torneiras) deve ser montado separadamente, ainda não pressuri-

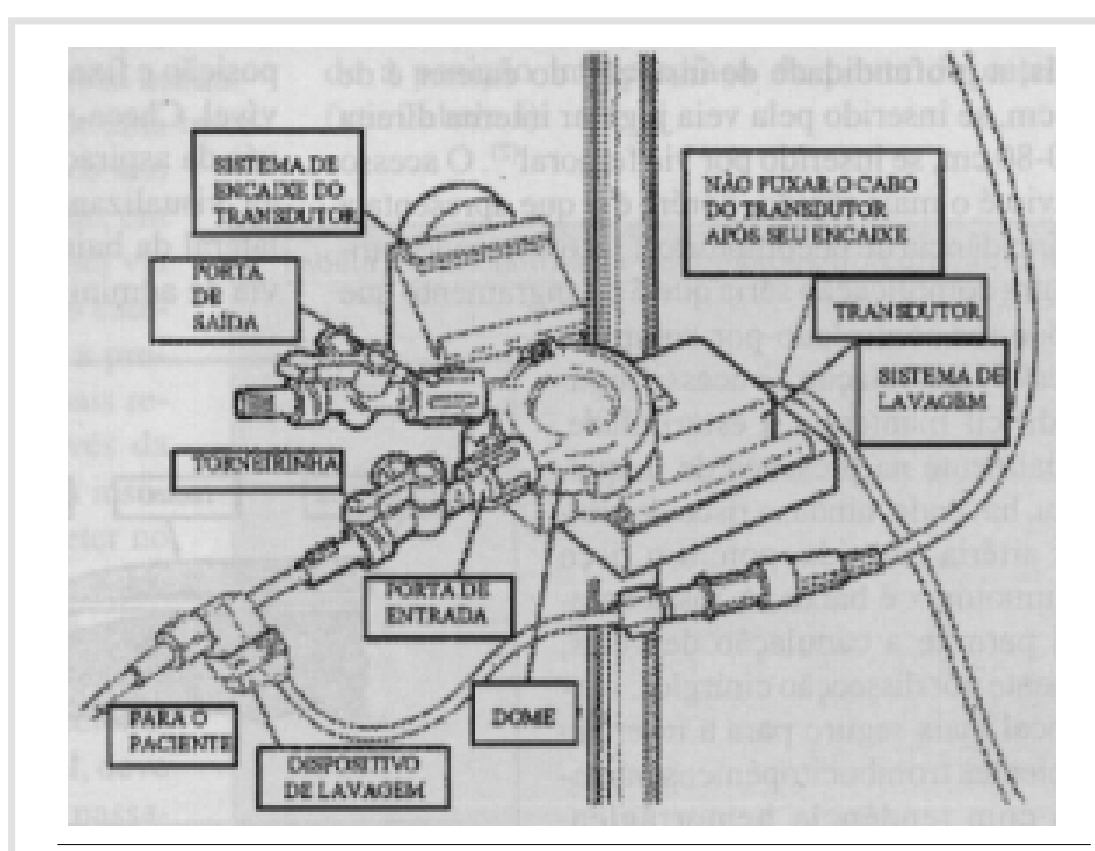

Figura 1 - Montagem do sistema de conexões e do transdutor de pressão. 
tante do sistema de conexão com solução salina. Por fim, o sistema deve ser pressurizado com $300 \mathrm{mmHg}$ na bolsa do sistema de lavagem.

Algumas observações na repleção do sistema de conexão, com solução salina, nos auxiliam ${ }^{(2,16)}$ :

a) conectar o sistema de conexão ao transdutor, antes de pressurizar o sistema (enchê-lo com salina);

b) remover o "dome" do transdutor, se necessário, quando o sistema está pressurizado, fechar a "torneirinha" para o paciente e qualquer outra fonte de pressão para impedir a distensão da membrana do "dome";

c) se for utilizada uma seringa para tal procedimento, deve ser de pelo menos $10 \mathrm{ml}$;

d) a "torneira" para a atmosfera deve estar aberta, quando o sistema está sendo enchido. O enchimento deve ser lento para a remoção mais eficiente das bolhas;

e) preencher todas as porções do sistema de conexão com solução salina estéril;

f) usar líquido aquecido para diminuir a ocorrência de bolhas espontâneas;

g) retirar, completamente, todas as bolhas do sistema de conexão, antes do seu uso.

\subsection{Locais de introdução}

O cateter de Swan-Ganz pode ser introduzido através de dissecção venosa (antecubital) ou por punção percutânea (veia jugular interna, veia subclávia e veia femoral), sendo este último método o mais recomendado devido à menor taxa de infecção e sangramento, no sítio de entrada do cateter. Em indivíduos normais, a profundidade de inserção do cateter é de $40-50 \mathrm{~cm}$, se inserido pela veia jugular interna direita e de $70-80 \mathrm{~cm}$, se inserido por via femoral ${ }^{(2)}$. O acesso subclávio é o mais rápido, porém é o que apresenta a maior incidência de pneumotórax (1 a 6\%), tendo também outra complicação séria que é o sangramento que não pode ser controlado por compressão local ${ }^{(3)}$. Em relação ao acesso jugular, é difícil manter-se a esterilidade, principalmente na presença de traqueostomia, havendo, ainda, o risco de punção da artéria carótida, porém o risco de pneumotórax é baixo. A fossa antecubital permite a canulação de veias, geralmente por dissecção cirúrgica, sendo o local mais seguro para a inserção em pacientes trombocitopênicos ou naqueles com tendência hemorrágica. Contudo, pode tornar-se difícil passar o cateter do braço à veia subclávia, ten- do, ainda, complicações locais, como flebite, estase venosa e maior risco de infecção em veias dissecadas. A via femoral tem maior risco de trombose venosa, profunda e embolização pulmonar ${ }^{(3)}$.

\subsection{Técnica}

Inicialmente, a técnica de introdução do cateter de Swan-Ganz ${ }^{(17)}$ assemelha-se a de uma punção venosa central, sendo necessária a antissepsia da área com iodo de polivinilpirrolidona (PVP-I), colocação de campo cirúrgico estéril, anestesia local com lidocaína, sendo a técnica e o local de punção venosa escolhidos de acordo com a experiência prática do seu executor. Os sítios mais comuns de punção são a veia jugular interna, direita ou a veia subclávia, direita.

Após o sucesso da punção venosa, introduzimos o fio guia de metal através do cateter de punção, retirando, em seguida, este cateter e deixando apenas o fio guia no interior da veia (verificar a presença de eventuais arritmias no monitor. Se presentes, recuar o fio guia). Nesse momento, fazemos uma pequena incisão com bisturi, no local de inserção do fio guia na pele, para que o dilatador possa passar após sua conexão ao fio guia, o que permite a sua introdução no trajeto subcutâneo e intravenoso de forma dirigida, dilatando o trajeto (ver Figura 2). A seguir, o dilatador é retirado do fio guia, mantendo-o dentro da veia. Agora, o dilatador é passado dentro da bainha do cateter e este conjunto é conectado ao fio guia, ainda em posição intravenosa, para dirigir o conjunto ${ }^{(17)}$. Quando todo o cateter foi introduzido, retiramos o dilatador e o fio guia do interior do cateter, mantendo este em posição e fixando-o à pele, com fio cirúrgico inabsorvível. Checa-se a posição intravenosa do cateter através da aspiração da via lateral do mesmo com seringa, visualizando o refluxo de sangue venoso. Essa via lateral da bainha do cateter pode ser utilizada como via de administração de volume ou drogas ${ }^{(3)}$. 
Só agora, após a punção venosa realizada e adequadamente fixada, é que vamos introduzir o cateter de Swan-Ganz através da bainha do cateter ${ }^{(17)}$. Para evitar a contaminação em posteriores manipulações do cateter, para acerto da posição dele, no momento de introdução do cateter de Swan-Ganz, passamos o mesmo através de uma "camisinha" protetora, estéril em seu interior, que se conecta à bainha do cateter introdutor através de um adaptador distal e fixa-se ao próprio cateter de Swan-Ganz através de um adaptador proximal (ver Figura 3).

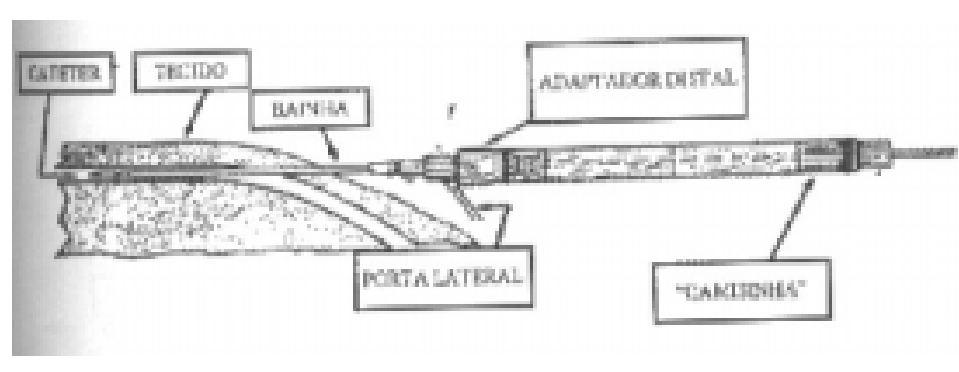

Figura 3 - Após a fixação do cateter, com sua bainha e porta lateral, 0 cateter de Swan-Ganz é passado dentro da "camisinha", antes de sua introdução.

O cateter de Swan-Ganz pode ser introduzido, também, a partir de uma punção venosa, central, previamente realizada. Para isso, basta retirar a fixação do cateter à pele, sendo mais fácil cortar o cateter logo abaixo do seu ponto de fixação, segurando-o com cuidado. Agora, o fio guia deve ser introduzido através do cateter e este retirado em seguida. A partir daí, seguimos o procedimento tal como descrito acima.

$\mathrm{Na}$ eventualidade de optarmos por uma inserção femoral do cateter, é recomendado o uso de fluoroscopia ${ }^{(2)}$. Deve ser lembrado que, em pacientes com dilatação atrial direita, esta via pode ser inapropriada pela facilidade do cateter de enrolar-se no átrio, dificultando a progressão até a artéria pulmonar, sendo mais recomendada a inserção do cateter através da veia cava superior. Na técnica, devemos insuflar o balão antes de avançar com o cateter no interior da veia cava inferior, facilitando o seu "deslizamento" e reduzindo a chance de o cateter tomar a direção da veia ilíaca oposta. Um outro detalhe técnico, para facilitar o direcionamento do cateter inserido por via femoral, deve ser lembrado, quando se torna difícil a passagem do cateter do átrio para o ventrículo direito, quando devemos alterar a orientação da ponta do cateter atra- vés de leve movimento rotacional e retirada simultânea do cateter por alguns centímetros, quando, então, o avançamos $^{(2)}$.

\subsection{Ondas de pressão}

O sinal da pressão sanguínea é transmitido via fluido, no interior do sistema de conexão, até o "dome", onde sensibiliza a superfície do transdutor. Nesse local, o sinal é convertido em um sinal elétrico, captado pelo monitor. Para a transmissão da pressão sanguínea ao transdutor e, por conseguinte, ao monitor ser mais preciso, com um sinal de melhor qualidade, é necessário tomar certos cuidados ${ }^{(8,16)}$ :

a) eliminar bolhas do sistema de conexão, que podem tanto distorcer a forma das ondas de pressão, quanto ser perigosas para a circulação sanguínea do paciente;

b) diminuir a extensão do sistema de conexão;

c) reduzir o número de "torneireinhas" ou conexões.

Como o cateter de Swan-Ganz, devidamente conectado a um sistema de conexão, preenchido com solução salina e conectado adequadamente a um transdutor e monitor de pressão, é introduzido através das câmaras cardíacas, as ondas de pressão características (tanto a forma das ondas, quanto a medida da pressão na câmara cardíaca) são obtidas, indicando a posição intracardíaca da ponta do cateter ${ }^{(2,3)}$ (ver Tabela I).

Tabela I - Faixas típicas de pressões no coração direito

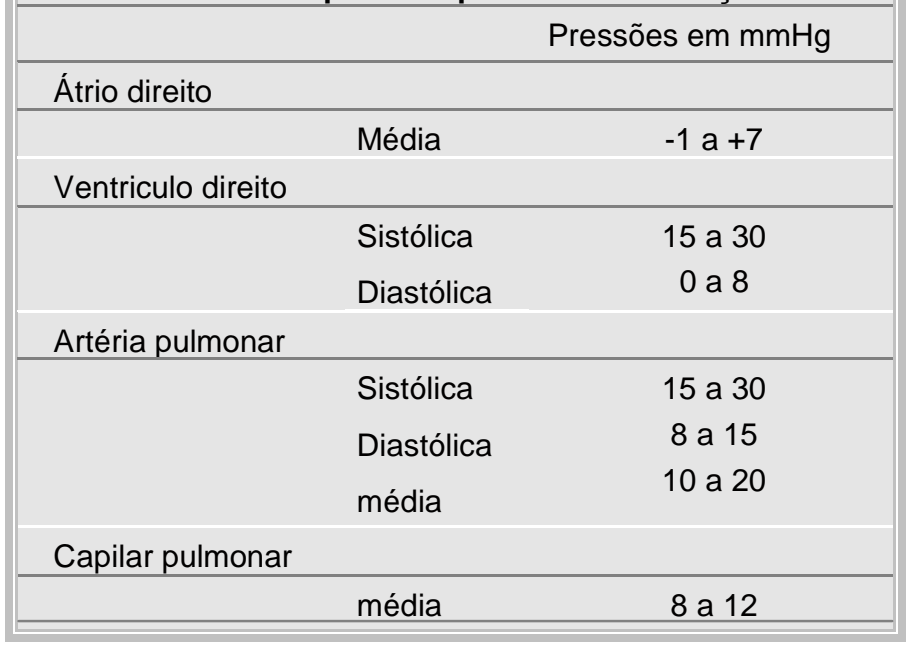


A monitorização simultânea do ritmo cardíaco é fundamental para se detectarem taquiarritmias ventriculares. Após o cateter atingir o átrio direito, o balão deve ser insuflado $(1,5 \mathrm{ml}) \mathrm{e}$, através da corrente sanguínea, passa pelo ventrículo direito e entra na artéria pulmonar (em qualquer um de seus ramos), verificando sua posição pela observação da forma das ondas (inflexão dicrótica, devido ao fechamento da válvula pulmonar, quando a pressão ventricular direita cai abaixo da pressão na artéria pulmonar) e pelo registro de sua pressão, até o seu encunhamento (reaparecimento da curva com características atriais), que ocorre quando um ramo da artéria pulmonar é ocluído e nenhum fluxo sangüíneo ocorre desde a extremidade do cateter até o ponto onde a veia pulmonar se une com outra veia pulmonar, que drena um ramo separado da artéria pulmonar, ipsilateral ${ }^{(2,3,8,9)}$ (ver Figura 4).

Como a pressão na veia pulmonar é quase idêntica à pressão atrial, esquerda, a pressão transmitida ao cateter, quando o balão é insuflado, é a do átrio esquerdo e, portanto, a pressão diastólica final do ventrículo esquerdo ${ }^{(3)}$ (ver Figura 5).

\subsection{Encunhamento do cateter}

Após obtermos um traçado de pressão capilar, pulmonar, pela lenta insuflação do balão, observando quando o traçado de pressão altera, o balão deve ser desinsuflado e tracionado até que um valor entre 1 e $1,5 \mathrm{ml}$ insuflado seja suficiente para o encunhamento ${ }^{(2,3)}$. Se menos de $1 \mathrm{ml}$ produzir um traçado de pressão capilar pulmonar, o cateter está localizado demasiado distalmente em um vaso periférico e deve ser tracionado de volta uns poucos centímetros $^{(2)}$. Quando desinsuflamos o balão, devemos observar o retorno da curva dicrótica da artéria pulmonar. $\mathrm{O}$ balão nunca deve permanecer insuflado, pois oclui o vaso, podendo causar infarto pulmonar ${ }^{(2)}$.
Quando inserido pela veia subclávia ou veia jugular interna, as distâncias típicas requeridas são: átrio direito, 10-15 cm; ventrículo direito, 20-30 cm; artéria pulmonar, 45-50 cm; e pressão capilar pulmonar, 50$55 \mathrm{~cm}^{(9)}$. Lembrar que a introdução excessiva do cateter contribui para a formação de nós e se não for obtido um traçado de pressão capilar pulmonar dentro dos $15 \mathrm{~cm}$ adicionais de inserção do cateter, devemos suspeitar da formação de uma alça de cateter ${ }^{(2)}$. Outros problemas possíveis são: o falso encunhamento, quando a ponta do cateter encrava em baixo da válvula pulmonar ou dentro de suas trabeculações (a sim-

Figura 4 - Forma das ondas e suas pressões normais, obtidas durante a introdução do cateter de Swan-Ganz, desde o átrio direito até o seu "encunhamento" no capilar pulmonar. 
ples retirada de alguns centímetros do cateter resolvem o problema) e a hiperinsuflação do balão, que pode fazê-lo herniar sobre a ponta do cateter, resultando num traçado de pressão que tende a altos níveis $^{(2)}$ (o balão deve ser desinsuflado e retirado por uma curta distância, sendo novamente introduzido).

A posição final da ponta do cateter dentro da artéria pulmonar é crucial para a adequada medida das pressões e realização dos cálculos hemodinâmicos.

O pulmão tem três zonas baseadas nas diferenças gravitacionais entre as pressões da via aérea $(\mathrm{PA})$ e vascular, arterial $(\mathrm{Pa})$ ou venosa $(\mathrm{Pv})^{(18)}$. Estas zonas são definidas fisiologicamente e não correspondem a divisões anatômicas fixas ${ }^{(3,8,9)}$. Na zona I (superior), a pressão média das vias aéreas (PA) é intermitentemente maior que a pressão venosa e arterial pulmonar, resultando no colapso da vasculatura entre a ponta do cateter e o átrio esquerdo. Na zona II (média), a PA é menor que a Pa, porém é maior que a $\mathrm{Pv}$. Nestas duas posições, a pressão observada é mais indicativa de pressão de via aérea do que da pressão atrial esquerda. Apenas na zona III (inferior), há uma ininterrupta coluna de sangue entre a ponta do cateter e o átrio esquerdo, permitindo a aferição confiável de sua pressão (ver Figura 6). Na posição supina, a zona III assume a posição mais dependente, caudal ao átrio. A diminuição da pressão, na via aérea, altera a relação ventilação-perfusão, produzindo um aumento na zona III e a hipovolemia diminui a pressão vascular e diminui a zona III, em relação às zonas I e II ${ }^{(3,9)}$.

A posição final correta do cateter de Swan-Ganz deve ser assegurada através da radiografia de tórax. A maioria dos cateteres migram caudalmente (zona III) e para a direita, durante a introdução ${ }^{(3)}$. Os cateteres localizados abaixo do nível do átrio esquerdo, conforme visto em radiografias laterais do tórax, geralmente, refletem, com precisão, a pressão de átrio esquerdo em todos os níveis de PEEP, mas os cateteres localizados ao nível ou acima do átrio esquerdo fornecem leituras inexatas, especialmente com PEEP.

Os indicadores de uma localização apropriada do cateter são ${ }^{(3,8,9)}$ :

- declínio na pressão, quando o cateter move da artéria pulmonar para a sua posição de encunhamento;
- capacidade de aspiração de sangue pela via distal do cateter, eliminando a possibilidade de hiperencunhamento;

- declínio na concentração expirada de $\mathrm{CO}_{2}$ com a insuflação do balão, produzida pelo aumento do espaço morto, alveolar;

- nível de pressão capilar, pulmonar, menor que a pressão média da artéria pulmonar, a pressão capilar pulmonar média pode ser maior que a pressão diastólica da artéria pulmonar, na insuficiência mitral;

- ausência de grandes variações do registro da pressão capilar, pulmonar, na dependência do tempo do ciclo ventilatório.

- um aumento da pressão capilar, pulmonar, menor que 50\% da redução efetuada nos níveis de PEEP (não devemos descontinuar a PEEP para a aferição da pressão capilar, pulmonar, pelo risco de hipoxemia e pelas alterações dos dados hemodinâmicos, pois aumentará o retorno venoso ao coração com a retirada do PEEP, elevando as pressões de enchimento);

- ausência de uma curva de pressão amortecida, que pode ocorrer pela presença de uma bolha na cúpula do transdutor, coágulos na extremidade do cateter e excesso de tubulação entre o transdutor e o cateter.

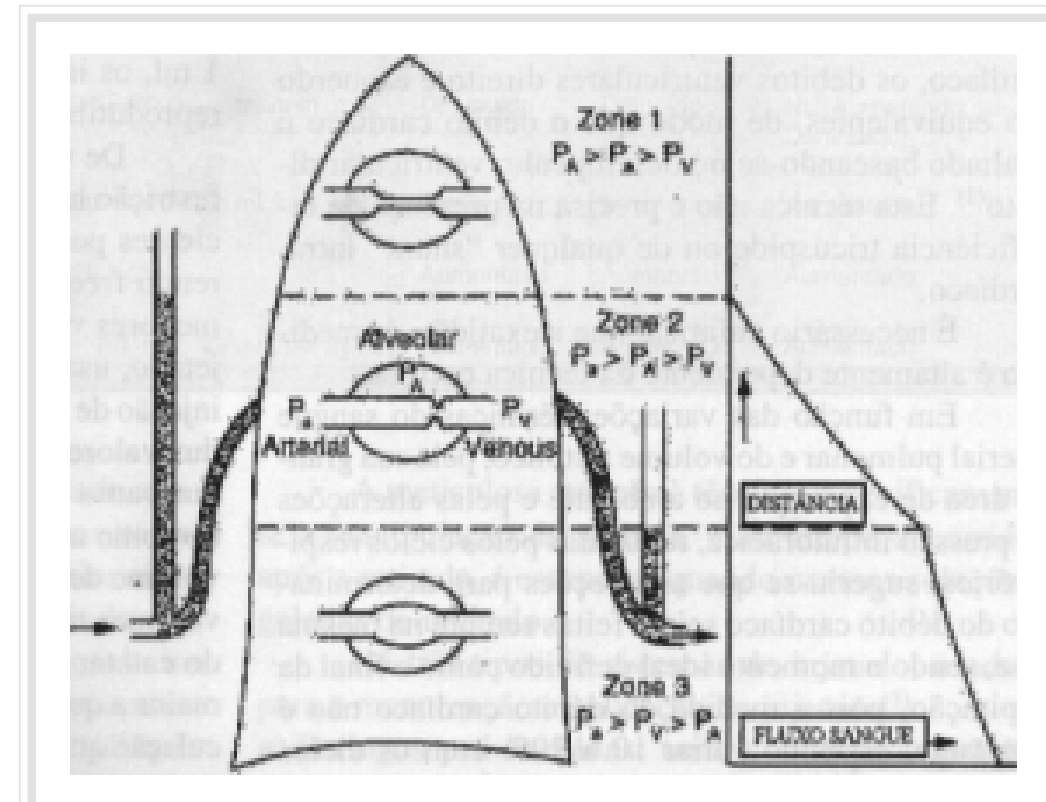

Figura 6 - O efeito da pressão das vias aéreas nos vasos pulmonares é dividido em três (3) zonas. O cateter de Swan-Ganz deve estar na zona III, onde há uma coluna contínua de sangue entre o capilar pulmonar e o átrio esquerdo. 


\subsection{Cálculos hemodinâmicos}

A pressão capilar pulmonar é a medida mais útil, pois estima a pressão de enchimento ventricular esquerdo e serve como uma estimativa da pré-carga ventricular. Uma vez que a vasculatura pulmonar forma um circuito de baixa resistência, a pressão diastólica final da artéria pulmonar é geralmente 1 - $3 \mathrm{mmHg}$ maior que a pressão capilar, pulmonar, média e pode ser usada para estimar a pressão ventricular, esquerda, quando a pressão capilar pulmonar não for disponível ${ }^{(3)}$.

O débito cardíaco é medido pela técnica de termodiluição, onde a injeção de uma quantidade conhecida de uma solução, a uma temperatura conhecida, mais fria que a temperatura corporal (em pelo menos $10^{\circ} \mathrm{C}$ ) é injetada na via proximal do cateter de SwanGanz (localizada no átrio direito), com resultante queda na temperatura do sangue, na extremidade do cateter, é usada para calcular o débito cardíaco, pela diminuição da resistência elétrica do termistor, que, eletronicamente, é descrita como uma curva e a área abaixo desta curva de termodiluição é integrada, calculada como débito cardíaco (pela fórmula de StewartHamilton de diluição de indicador) e exibida no computador em litros por minuto ${ }^{(3)}$.

Um sensor de referência do injetado, partindo do computador do débito cardíaco, é colocado nas mesmas condições de temperatura que a da solução do injetado.

Na realidade, está sendo medido o débito ventricular direito, pois que, na ausência de desvio intracardíaco, os débitos ventriculares direito e esquerdo são equivalentes, de modo que o débito cardíaco é avaliado baseando-se no desempenho ventricular direito $^{(3)}$. Esta técnica não é precisa na presença de insuficiência tricúspide ou de qualquer "shunt" intracardíaco.

É necessário enfatizar que a exatidão da medição é altamente dependente da técnica correta.

Em função das variações térmicas do sangue arterial pulmonar e do volume sistólico, pela sua grande área de exposição ao ambiente e pelas alterações na pressão intratorácica, induzidas pelos ciclos respiratórios, sugeriu-se que as injeções para determinação do débito cardíaco sejam feitas sempre na mesma fase, sendo o momento ideal definido como o final da expiração, pois a medida do débito cardíaco não é constante, podendo variar 10 a $20 \%$ com os ciclos respiratórios ${ }^{(3,8,9,19)}$. Em cada inspiração, a temperatura do sangue, na artéria pulmonar, assim como o débito cardíaco, aumenta (o inverso da relação ocorre durante a ventilação mecânica) ${ }^{(19)}$. Na prática clí- nica, a dificuldade de sincronização com uma determinada fase do ciclo ventilatório justifica a realização de, pelo menos, três (3) injeções seqüenciais, para posterior determinação do valor médio, minimizando erros potenciais ${ }^{(3,19)}$.

A frequiente medida do débito cardíaco, em doentes graves, permite o acompanhamento e manipulação de outras variáveis hemodinâmicas, como a resistência vascular, pulmonar e sistêmica e o trabalho sistólico, além de uma função da circulação, que é o transporte de oxigênio (ver Tabela II).

\subsection{Temperatura do líquido a ser injetado}

Embora a eficácia do método tenda a aumentar proporcionalmente ao resfriamento da solução injetada, a utilização de $10 \mathrm{ml}$ de soluções (SG 5\% ou SF $0,9 \%$ ) em temperatura ambiente (mantendo um diferencial térmico de, pelo menos, $10^{\circ} \mathrm{C}$ em relação à temperatura corpórea) simplifica o método sem perda de confiabilidade ou precisão ${ }^{(20,21)}$. Adicionalmente, a utilização de soluções resfriadas pode trazer inconvenientes, como o aquecimento do volume injetado, à medida em que é retirado através da tubulação quente, pelo manuseio da seringa ou demora na injeção, aumento do custo e do tempo necessários para o preparo e manutenção da temperatura da solução (leva de quarenta e cinco (45) a sessenta (60) minutos para que as seringas ou bolsas de infusão em um banho gelado atinjam o equilíbrio a 0 a $4^{\circ} \mathrm{C}$ ) e o potencial arritmogênico $^{(3,20,21)}$. Quando são usados volumes de 5,3 e 1 $\mathrm{ml}$, os injetados gelados podem resultar em maior reprodutibilidade do que à temperatura ambiente ${ }^{(3)}$.

De um modo geral, em pacientes adultos, sem restrição hídrica, usam-se volumes de $10 \mathrm{ml}$. Para pacientes pediátricos ou com restrição hídrica, requerendo frequientes determinações do débito cardíaco, menores volumes podem ser usados ${ }^{(3)}$. O volume injetado, usado deve ser medido com precisão, pois a injeção de menos indicador do que o especificado produz valores de débito cardíaco falsamente altos, porque causa menos resfriamento do sangue, interpretado como um fluxo mais alto do que o real ${ }^{(3)}$. Erros no volume de injetado introduzido são minimizados por volumes maiores (ex.: $10 \mathrm{ml}$ ), além do espaço morto do cateter conter uma quantidade do injetado, sendo maior a quantidade de indicador fornecida para a circulação quanto maior o volume de injetado. Uma fonte freqüente de erro de volume ocorre quando o volume injetado vaza no local de conexão ao cateter ou torneira, durante a injeção forçada. Se isto ocorrer, estes valores devem ser desprezados e as medições repetidas ${ }^{(3)}$. 


\begin{tabular}{|c|c|c|c|c|c|}
\hline Variável & Valor normal & Unidade & $\begin{array}{c}\text { Choque } \\
\text { Hipovolêmico }\end{array}$ & $\begin{array}{c}\text { Choque } \\
\text { cardiogênico }\end{array}$ & Choque séptico \\
\hline Pressão arterial média (PAM) & $82-102$ & $\mathrm{MmHg}$ & Diminuida & Diminuida & Diminuda \\
\hline Frequência cardíaca (FC) & $72-88$ & Bat./min & Aumentada & Aumentada & Aumentada \\
\hline Pressão venosa central (PVC) & $0-9$ & $\mathrm{Cm} \mathrm{H} 2 \mathrm{O}$ & Diminuida & Aumentada & $\begin{array}{l}\text { NL, Aumentada ou } \\
\text { Diminuida }\end{array}$ \\
\hline Pressão capilar pulmonar (PCP) & $0-12$ & $\mathrm{Mm} \mathrm{Hg}$ & $\begin{array}{l}\text { Normal ou } \\
\text { Diminuida }\end{array}$ & Aumentada & $\begin{array}{l}\text { NL, Aumentada ou } \\
\text { Diminuida }\end{array}$ \\
\hline Índice cardíaco (IC) & $2,8-4,0$ & $\mathrm{~L} / \mathrm{min} . \mathrm{m}-2$ & Aumentado & Diminuido & $\begin{array}{l}\text { NL, Aumentada ou } \\
\text { Diminuida }\end{array}$ \\
\hline Índice sistólico (IS) & $35-50$ & $\mathrm{~mL} / \mathrm{m}-2$ & Diminuido & Diminuido & $\begin{array}{l}\text { NL, Aumentada ou } \\
\text { Diminuida }\end{array}$ \\
\hline Resistência vascular sistêmica (RVS) & $770-1500$ & dina.seg/cm-5 & Aumentado & Aumentado & Diminuido \\
\hline Resistência vascular pulmonar (RVP) & $50-200$ & dina.seg/cm-5 & Aumentado & Aumentado & $\begin{array}{l}\text { NL, Aumentada ou } \\
\text { Diminuida }\end{array}$ \\
\hline Saturação arterial de oxigênio (Sat. O2) & $95-99$ & $\%$ & $\begin{array}{l}\text { Normal ou } \\
\text { Diminuida }\end{array}$ & $\begin{array}{l}\text { Normal ou } \\
\text { Diminuida }\end{array}$ & $\begin{array}{l}\text { Normal ou } \\
\text { Diminuida }\end{array}$ \\
\hline Saturação venosa mista de oxigênio (Satv. O2) & $68-75$ & $\%$ & Diminuida & Diminuida & $\begin{array}{l}\text { NL Aumentada ou } \\
\text { Diminuida }\end{array}$ \\
\hline Oxigênio venosa misto (PvO2) & $33-53$ & $\mathrm{MmHg}$ & Diminuido & Diminuido & $\begin{array}{l}\text { NL, Aumentada ou } \\
\text { Diminuida }\end{array}$ \\
\hline Diferença arteriovenosa de oxigênio $+\mathrm{D}(\mathrm{a}-\mathrm{v}) \mathrm{Os}$ & $4-5,5$ & $\mathrm{~mL} / \mathrm{dL}$ & Aumentada & Aumentada & Aumentada \\
\hline Oferta de oxigênio (DO2) & $520-700$ & $\mathrm{~mL} / \mathrm{min} . \mathrm{m}-2$ & Diminuido & Diminuido & $\begin{array}{l}\text { NL, Aumentado ou } \\
\text { Diminuido }\end{array}$ \\
\hline Consumo de oxigênio (DO2) & $180-300$ & $\mathrm{~mL} / \mathrm{min} . \mathrm{m}-2$ & Diminuido & Aumentado & Aumentado \\
\hline Índice de extração de oxigênio (ER O2) & $20-25$ & $\%$ & Aumentado & Aumentado & Aumentado \\
\hline Lactato sérico & 2,1 & $\mathrm{mmol} / \mathrm{L}$ & Aumentado & Aumentado & Aumentado \\
\hline
\end{tabular}

O indicador, na prática, pode ser injetado através de uma torneira em vez de diretamente na abertura da via proximal do cateter, o que traz maior risco de contaminação. Se a injeção for feita através de uma torneira e for usado injetado gelado, a seringa do injetado deve ser conectada ao orifício da torneira mais próxima da porta da via proximal do cateter, a fim de minimizar o espaço morto da torneira, que está em temperatura ambiente. Com menos de $5 \mathrm{ml}$ de injetado gelado, pode ser aconselhável injetar diretamente na via proximal do cateter ${ }^{(3)}$.
A meticulosa atenção à técnica, especificamente à manipulação da seringa, e ao tempo decorrido após a retirada, é essencial ,quando usamos soluções geladas de injetado.

Há três tipos de sistemas de injetado, usados para a manutenção e aplicação de injetado ${ }^{(3)}$ :

a) Seringas pré-enchidas: tanto com líquido gelado quanto à temperatura ambiente, têm a desvantagem potencial de contaminação do conteúdo da seringa.

b) Sistemas abertos: para injetado em temperatura gelada, dois frascos ou bolsas de infusão intra- 
venosa (SG 5\% ou SF 0,9\%) armazenados em um banho gelado, onde um dos frascos é mantido como fonte estéril, da qual o injetado é aspirado imediatamente, antes de efetuar uma medição do débito cardíaco. O sensor de temperatura do injetado é colocado no segundo frasco/bolsa (não estéril), mantido no mesmo ambiente gelado. A temperatura de cada frasco/bolsa, apesar da remoção do líquido da bolsa de injetado, não deve variar mais do que $0,5^{\circ} \mathrm{C}$. $\mathrm{O}$ injetado pode ser aspirado por uma agulha introduzida no frasco/bolsa ou por algum tipo de tubulação de extensão endovenosa (a tubulação deve também ser imersa no banho gelado). A própria seringa deve ser pré-resfriada, aspirandose solução fria para a frente e para trás, várias vezes (que é outra fonte de aquecimento do injetado). Um risco de crescimento microbiano é um risco potencial.

c) Sistemas fechados: existem, comercialmente disponíveis, sistemas que apresentam um conduto estéril desde a fonte do injetado até o cateter, e são ideais para soluções de injetado à temperatura gelada. Isto minimiza muitos dos erros de temperatura comumente associados com injetado gelado. Para injetados em temperatura ambiente, os sistemas fechados podem ser facilmente montados a um custo mínimo. O risco de contaminação é expressivamente menor que o sistema aberto. Estes sistemas fechados devem ser trocados a cada quarenta e oito (48) horas.

O tempo gasto no processo de cada injeção é pouco relevante, se for menor que quatro (4) segundos.

\subsection{Procedimento}

A extremidade do cateter e o termistor devem estar em posição adequada, num dos ramos da artéria pulmonar. Esta avaliação é feita tanto radiograficamente, quanto observando-se as ondas de pressão da artéria pulmonar e da pressão capilar pulmonar. Se a extremidade do cateter encravar sem a insuflação do balão (ex.: muito avançado na artéria pulmonar), o termistor pode não ser exposto ao volume inteiro de indicador após a injeção, por estar em contato com a parede do vaso, resultando em curvas irregulares, fornecendo medições de débito cardíaco, falsamente elevadas. As medidas do débito cardíaco não devem ser feitas com o balão insuflado.
A localização do orifício proximal da luz (via proximal do cateter) no átrio direito também é um fator importante de exatidão técnica. Sua localização abaixo do átrio direito pode resultar em um misturamento incompleto do indicador com o fluxo sanguíneo total que passa diante do termistor, fornecendo falsos resultados. A localização do orifício proximal da luz, acima do átrio direito, pode resultar em perda do indicador, antes da detecção pelo termistor, novamente fornecendo falsos resultados. A verificação do orifício da luz proximal é obtida, observando-se uma onda atrial, direita, no osciloscópio. Lembrar que existem disponíveis cateteres com várias localizações de orifício proximal e esta é uma consideração importante ao serem selecionados cateteres para adultos muito pequenos e para crianças.

Um outro fator de erro na medida do débito cardíaco ocorre se a bainha do cateter (geralmente de $15 \mathrm{~cm}$ ) cobrir o orifício proximal (via proximal), pois o indicador pode não ser liberado rápida ou inteiramente, na circulação, dando um valor erroneamente alto no débito cardíaco. Isto é mais fácil de ocorrer na inserção do cateter pela veia jugular interna ou subclávia direita.

Ainda podem ocorrer erros de medição por termodiluição, se líquidos intravenosos forem infundidos através dos ramos laterais da bainha do cateter, durante o cálculo do débito cardíaco. A magnitude do erro depende do volume e temperatura da solução que está sendo infundida. Estas soluções devem ser temporariamente reduzidas, antes e durante as determinações do débito cardíaco.

A técnica de termodiluição refletirá o débito cardíaco em qualquer posição ${ }^{(22)}$. Para constância e comparação, as determinações do débito cardíaco devem ser obtidas na mesma posição na qual os outros parâmetros hemodinâmicos foram obtidos.

Além disso, o computador deve estar no modo de medição e com a constante correta estocada. A constante é dada pelo número do modelo do cateter e a temperatura e o volume do injetado, sendo necessário consultar a tabela de referência do fabricante ${ }^{(23)}$. Esta informação pode ser obtida no manual do computador ou no folheto que acompanha a embalagem do cateter. Esta constante leva em consideração uma correção para as unidades de medição (litros/minuto), espaço morto do injetado ou da via proximal, transferência de calor, velocidade de injeção e volume e temperatura do injetado. 
Deve-se tomar cuidado com a retirada do injetado. Se for usado injetado à temperatura ambiente, o bolo pode ser retirado a qualquer momento, desde que a seringa cheia permaneça a temperatura ambiente. Se for usado injetado gelado, o bolo para injeção deve ser retirado da fonte de solução rapidamente e injetado imediatamente (em menos de quinze (15) segundos), a fim de evitar aquecimento. Evitar segurar a seringa cheia na mão, pelo risco de transferência de calor, induzindo um erro técnico.

O computador é ativado e a solução é injetada. A injeção deve ser suave e contínua, sem parar ou mudar a velocidade de injeção e completada dentro de dois (2) a quatro (4) segundos. Estes aspectos da técnica de injeção são cruciais para a exatidão e reprodutibilidade do método.

A forma da curva é de vital importância, porque é a área debaixo da curva que é integrada. Uma curva normal é lisa e consiste tipicamente em uma ascensão rápida ou pico, seguida por uma descida mais lenta e retorno à linha de base. Curvas lisas e contínuas são obtidas mais comum e facilmente quando a pressão no êmbolo é aplicada com a eminência tenar, em vez de com o próprio polegar ${ }^{(3)}$.

$\mathrm{Na}$ maioria das situações, injeções na circulação central estão contra-indicadas na presença de comunicação intracardíaca ${ }^{(3)}$. Na presença de desvio da direita para a esquerda, o indicador injetado na átrio direito pode ser "perdido" para o lado esquerdo do coração e jamais passar pelo termistor, resultando em valores de débito cardíaco falsamente elevados. $\mathrm{Na}$ presença de desvio da esquerda à direita, pode ocorrer recirculação de frio, quando o sangue "resfriado", fluindo através do coração direito e artéria pulmonar, atinge o lado esquerdo do coração, passa de volta ao lado direito e, a seguir, é recirculado através da artéria pulmonar, passando pelo termistor, o que produz um segundo pico na curva de termodiluição, a qual se torna ininterpretável pelo computador. Em um paciente que possa ter um defeito septal não diagnosticado, os achados descritos, após injeções de termodiluição, podem alertar para esta possibilidade ${ }^{(3)}$.

Na presença de insuficiência tricúspide ou pulmonar, a técnica de termodiluição pode não ser exata, devido à perda de indicador por fluxo retrógrado ${ }^{(9)}$.

\section{COMPLICAÇÕES}

As complicações associadas com o cateterismo da artéria pulmonar podem ser divididas em ${ }^{(3,8,9)}$ : a) relacionadas à punção venosa:

- punção arterial;

- pneumotórax;

- lesão do plexo braquial;

- síndrome de Horner;

- lesão transitória do nervo frênico;

- embolia gasosa.

b) relacionadas à passagem do cateter:

- arritmias (extra-sístoles ventriculares, taquicardia e fibrilação ventriculares e flutter e fibrilação atrial);

- bloqueio transitório de ramo direito;

- enovelamento;

- danos nos sistemas valvares (cúspides, cordas tendíneas e músculos papilares);

- ruptura da artéria pulmonar;

- perfuração ventricular direita.

c) relacionadas à presença do cateter na artéria pulmonar:

- trombose venosa no local de inserção;

- infarto pulmonar;

- sepse / endocardite.

As arritmias ocorrem em 12 a $67 \%$ das cateterizações, sendo mais comum as extra-sístoles, ventriculares, autolimitadas, quando o cateter entra no ventrículo direito ${ }^{(3)}$. Um tempo de cateterização prolongado aumenta a sua incidência e a insuflação completa do balão previne a protrusão da extremidade do cateter na parede ventricular, direita, prevenindo a ectopia. O paciente, com bloqueio do ramo esquerdo, preexistente, pode desenvolver bloqueio cardíaco, completo, estando indicada a inserção profilática de um marcapasso, antes da cateterização ${ }^{(2,3)}$.

A manutenção da insuflação do cateter pode formar um infiltrado pulmonar, em forma de cunha distal, à extremidade do cateter, sugerindo infarto pulmonar ${ }^{(3)}$. Devemos limitar ao mínimo o tempo no qual o balão está insuflado para a aferição da pressão capilar, pulmonar, a não mais do que dois ciclos respiratórios ou dez (10) a quinze (15) segundos, no máxi$\mathrm{mo}^{(2)}$. A utilização de um sistema de irrigação contínua, com heparina e os novos cateteres com liga de heparina reduziram a incidência de infarto pulmonar.

A ruptura da artéria pulmonar pode ocorrer durante a insuflação do balão. A hipertensão pulmonar crônica, idade acima de sessenta (60) anos, anticoagulação, encunhamento excessivo do cateter e hiperinsuflação do balão aumentam o risco de ruptu$\mathrm{ra}^{(2,3)}$. Qualquer hemoptise, em um paciente com um 
cateter de Swan-Ganz, deve sugerir o diagnóstico de perfuração ou ruptura da artéria pulmonar ${ }^{(3)}$. Uma radiografia de tórax, muitas vezes, revela um infiltrado em torno da extremidade do cateter, se tiver ocorrido ruptura arterial. No quadro clínico, a gravidade é variável ${ }^{(24)}$. As opções de tratamento incluem a aplicação de PEEP ipsilateral, tamponamento endobrônquico, colocação de um tubo endotraqueal, de duplo lúmen, tamponamento interno da artéria pulmonar afetada com o balão do cateter de Swan-Ganz, e opções cirúrgicas, tais como a oclusão unilateral da artéria pulmonar, lobectomia ou a pneumectomia ${ }^{(24)}$. O fator crítico no manuseio da hemoptise maciça é a identificação do sítio de sangramento. A hemoptise por ruptura da artéria pulmonar pode ser tão intensa que a exsanguinação ocorre dentro de poucos minutos ${ }^{(3)}$.

Quanto mais tempo o cateter permanece no local, maior é o risco de ruptura do balão. Quando a tentativa de insuflação do balão não encontra a resistência usual, deve-se suspeitar de ruptura. Se aspirado sangue através da luz do balão, ele está roto. Quando suspeitamos de um "shunt" direita-esquerda, o balão deve ser insuflado com $\mathrm{CO}_{2}$, não ar, durante a medição da pressão capilar pulmonar ${ }^{(3,8)}$.

As infecções relacionadas com o cateter são mais comuns quando o cateter é deixado no lugar por mais de três (3) ou quatro (4) dias e podem ser mais comuns se tiver existido uma fonte conhecida de infecção, antes da inserção do cateter. $\mathrm{O}$ cateter deve permanecer no local o mínimo tempo requerido pelas condições do paciente. $\mathrm{O}$ fabricante recomenda o uso até setenta e duas (72) horas ${ }^{(2)}$, embora relatos recentes, na literatura médica, orientam o uso do cateter de Swan-Ganz e dos transdutores descartáveis por até quatro (4) dias ${ }^{(25)}$, sendo que as soluções de irrigação são trocadas a cada vinte e quatro (24) horas. Em nossa experiência, o cateter de Swan-Ganz deve ser deixado durante o intervalo de tempo necessário, enquanto as medidas de suporte avançado de vida estão sendo empregadas. Contudo, a melhora progressiva ou a eventual estabilização dos parâmetros hemodinâmicos, associadas à melhora do transporte de oxigênio e do "shunt" pulmonar indicam que o cateter cumpriu o seu papel e, assim, o cateter pode ser retirado.

A presença de dispnéia, dor torácica, taquicardia, sibilos expiratórios e déficits neurológicos, focais, associados a pressões elevadas no coração direito, hipotensão, hipoxemia e hipercarbia fazem suspeitar de um embolismo aéreo. A colocação do paciente em decúbito lateral esquerdo permite que o ar que está obstruindo o trato de saída pulmonar flutue para o ápice ventricular, aliviando a obstrução $0^{(3)}$. A aspiração do ar através do cateter venoso central e a administração de oxigênio a $100 \%$ (que faz diminuir o tamanho do êmbolo aéreo) também são medidas efetivas. Se a embolia aérea for muito importante, somente a oxigenioterapia hiperbárica a $2 \mathrm{Atm}$ de pressão, reduz o quadro. A embolização pode ser prevenida, colocando-se o paciente na posição de Trendelemburg, antes da colocação da linha venosa central e instruindo-o para prender a respiração durante a inserção do introdutor.

Devemos sempre observar se a extensão do cateter inserido correlaciona-se com as alterações dos traçados típicos de pressão, nas diferentes localizações $^{(2)}$. Se o ventrículo direito não foi atingido, quando $15 \mathrm{~cm}$ de cateter foram introduzidos, após o registro da pressão atrial direita, o cateter pode ter feito uma alça, dobrado ou sua extremidade distal ter ficado presa a uma veia cervical, permitindo que apenas o corpo do cateter entre no coração como uma alça. O nó intracardíaco do cateter pode ocorrer durante a sua inserção, pelo excessivo comprimento do cateter introduzido $^{(2)}$. A inserção de um longo fio guia, seguida pela lenta retirada do cateter sobre o fio, pode resolver o problema. Se esta manobra falhar, remover o fio guia, puxar apertadamente o cateter de encontro ao introdutor (para diminuir o tamanho do nó) e retirá-lo. Se não conseguir retirar através do introdutor, remover o introdutor e tracionar o cateter para fora, através da pele ${ }^{(3)}$.

\section{CONCLUSÕES}

Embora tenham surgido muitos artigos na literatura médica, recente, questionando a validade do uso do cateter de Swan-Ganz, nas suas diversas indicações, temos notado, na prática clínica diária, que ele tem um papel fundamental na avaliação e monitorização do paciente grave, permitindo um ajuste fino da reposição volêmica e titulação das doses de aminas vasoativas. A decisão sobre o seu uso deve ser precoce, assim que o paciente começar a apresentar instabilidade hemodinâmica, mantendo-se oligúrico ou anúrico, mesmo com o uso abundante de soluções colóides e cristalóides, além do início das aminas vasoativas, sem o sucesso esperado, tanto na recuperação da diurese, quanto dos níveis pressóricos. 
PEREIRA Jr. GA et al. Thermodiluition cardiac output measurements. Medicina, Ribeirão Preto, 31: 380-399, july/sept. 1998.

ABSTRACT: The purpose of this paper is to review the aspects concerning the invasive hemodynamic monitoring of the Swan-Ganz catheter. This routine, at the bedside, will be analysed regarding its indications, its insertion techniques, the checking of this position - through the surveillance of the pressure waves and the pulmonary capillary wedge pressure, and the thorax radiography - and its steps for the hemodynamic measurements, examining the main error factors that can be perpetrated, and the possible complications succeeding that procedure.

UNITERMS: Pulmonary Artery. Catheterization. Swan-Ganz, Catheterization. Hemodynamics. Pulmonary Wedge Pressure. Thermodilution Cardiac Output.

\section{REFERÊNCIAS BIBLIOGRÁFICAS}

1 - SWAN HJC et al. Catheterization of the heart in man with use of a flow-directed balloon-tipped catheter. N Engl J Med 283: 447-451, 1970.

2 - ABBOTT (CRITICAL CARE SYSTEMS). Thermodilution catheter: directions for use. Abbott Laboratories: Hospital Products Division, North Chicago, 1991.

3 - CHERYL AC et al. Monitorização hemodinâmica: cateteres de artéria pulmonar. In: CIVETTA JM; TAYLOR RW \& KIRBY RR, eds. Tratado de terapia intensiva, Manole, São Paulo, p. 341-351 e 419-436, 1992.

4 - ARAÚJO S. Riscos e benefícios dos procedimentos em UTI: Uma avaliação crítica da Monitorização do Sistema Cardiocirculatório. Clín Bras Ter Intensiva 3: 267-304, 1996.

5 - PULMONARY ARTERY CATHETER CONSENSUS CONFERENCE PARTICIPANTS. Pulmonary Artery Catheter Consensus Conference: Consensus Statement. Crit Care Med 25: 910-925, 1997.

6 - AMERICAN SOCIETY OFANESTHESIOLOGISTS TASK FORCE ON PULMONARY ARTERY CATHETERIZATION. Practice guidelines for pulmonary artery catheterization. Anesthesiology 78: 380-394, 1993.

7 - GNAEGI A et al. Intensive care physicians' insufficient knowledge of right-heart catheterization at the bedside: Time to act? Crit Care Med 25: 213-220, 1997.

8 - FERNANDES JR. CJ et al. Monitorização hemodinâmica. In: KNOBEL $E$, ed. Condutas no paciente grave, Atheneu, São Paulo, p. 156-174, 1994.

9 - BONGARD FS et al. Critical care monitoring. In: BONGARD FS \& SUE DY, eds. Current: critical care diagnosis \& treatment, Appleton \& Lange, Connecticut, p. 170-190, 1994.

10 - CONNORS AF Jr et al. The effectiveness of right heart catheterization in the initial care of critically ill patients. JAMA 276: 889-897, 1996.

11 - CHERNOW B. Pulmonary artery flotation catheters: A statement by the American College of Chest Physicians and the American Thoracic Society. Chest 111: 261-262, 1997.

12 - JARDIN F et al. Right heart catheterization at bedside: a critical view. Intensive Care Med 21: 291- 295, 1995.

13 - FEIHL F et al. Right heart catheterization at bedside: a note of cautious optimism. Intensive Care Med 21: 296-298, 1995.
14 - EIDELMAN LA et al. Pulmonary artery catheterization - at the crossroads ? Crit Care Med 22: 543-545, 1994.

15 - SCHNEIDER AJ et al. Biventricular performance during volume loading in patients with early septic shock, with emphasis on the right ventricule: A combined hemodynamic and radionuclide study. Am Heart J 116: 103-112, 1988.

16 - HEWLETT PACKARD. Operating instructions for using the Model 1290C Transducer and the Model 1295C. Disposable Dome. Hewlett Packard, Walthoni, Massachusetts, 1985.

17 - BAXTER. Tuohy-Borst Valve Introducer Products. Baxter Healthcare Corporation, Irvine, Calefornia, 1990.

18 - WEST JB. Effects of changes in topographical distribution of lung blood flow on gas exchange. J Appl Physiol 20: 825-835, 1965.

19 - STEVENS JH et al. Thermodilution Cardiac Output Measurement - Effects of the Respiratory Cycle on its Reproducibility. JAMA 253: 2240-2242, 1985.

20 - GROOM L et al. Injectate temperature: effects on thermodiluition CO measurements. Critical Care Nurse 10: 112-120, 1990.

21 - DAILY EK et al. Thermodilution cardiac outputs using room and ice temperature injectate: Comparison with the Fick method. Heart Lung 16: 294-300, 1987.

22 - GROOM L et al. Reproducibility and accuracy of pulmonary artery pressure measurements in supine and lateral positions. Heart Lung 19: 147-151, 1990.

23 - ABBOTT (CRITICAL CARE SYSTEMS). Indications, Contraindications and Computation Constants. Abbott Laboratories: Hospital Products Division, North Chicago, 1991.

24 - KLAFTA JM et al. Emergent lung separation for management of pulmonary artery rupture. Anesthesiology 87: 1248-1250, 1997.

25 - NORWOOD SH. Prevalência e importância das infecções nosocomiais. In: CIVETTA JM; TAYLOR RW \& KIRBY RR, eds. Tratado de terapia intensiva, Manole, São Paulo, p. 875-887, 1992.

Recebido para publicação em 04/03/98

Aprovado para publicação em 13/05/98 


\title{
Apêndice
}

\section{CÁLCULOS DOS PARÂMETROS FISIOLÓGICOS E RELATÓRIO DE MONITORIZAÇÃO HEMODINÂMICA INVASIVA}

\author{
PHYSIOLOGICAL PARAMETERS CALCULATIONS AND \\ INVASIVE HEMODYNAMIC MONITORING REPORT
}

Anibal Basile-Filho

A obtenção de determinados parâmetros hemodinâmicos, fisiológicos é, algumas vezes, de crucial importância no manuseio do paciente crítico. Dessa maneira, a partir de dados obtidos por monitorização hemodinâmica invasiva, através do cateter de Swan-Ganz ${ }^{(1)}$, associados aos valores das gasometrias do sangue arterial e venoso, pode-se calcular uma enorme série de parâmetros de forma simples, baseados em constantes fisiológicas, conhecidas, traduzidas por equações matemáticas complexas. Esses cálculos podem ser efetuados manualmente, utilizando-se uma calculadora programável, porém o tempo dispendido é grande. Dada a necessidade de se conhecerem esses parâmetros rapidamente, o que permite ao intensivista tomar decisões importantes e imediatas, foi desenvolvido, pela Disciplina de Terapia Intensiva do Departamento de Cirurgia, Ortopedia e Traumatologia da FMRP-USP, um relatório para a obtenção de parâmetros hemodinâmicos, baseados no programa Excel, versão 7.0 (Microsoft Office, Microsoft Co., EUA) para os sistemas operacionais Windows 3.1 ou 95 de 16 bits ou 32 bits (Microsoft Co., EUA) e um microcomputador do tipo Pentium (Intel Co., EUA) com 8 a $32 \mathrm{MB}$ de RAM.

Assim, o objetivo do presente artigo é fornecer um método de cálculo dos diversos parâmetros hemodinâmicos, obtidos à beira do leito, de fácil execução, através da introdução do cateter de Swan-Ganz. No entanto, as técnicas de inserção do cateter, suas indicações e contra-indicações, assim como o comportamento das diversas variáveis, obtidas nos diversos estados de choque circulatório, foram descritas, com detalhes, no tópico anterior do presente Simpósio de Terapia Intensiva.

\section{Dados de Entrada}

Conforme pode ser visto na Figura 1, a planilha (workbook) do programa Excel 7.0 é composta por colunas verticais (por exemplo, coluna A, B, C, D...) e linhas horizontais (por exemplo, linha 1, 2, 3, 4..). Cada célula corresponde a uma informação diferente (por exemplo, célula B13 = altura do paciente em $\mathrm{cm}$, indicando a coluna A e a linha 13), aceitando equações matemáticas complexas. De maneira extremamente simples, é solicitado ao intensivista que entre nas células com valores em itálico, alguns dados pessoais e antropométricos do paciente estudado, como nome (célula A9), idade (B9), sexo (C9), peso corpóreo (B12), altura (B13) e data do cálculo (A10). Além disso, é necessária a digitação de alguns dados fisiológicos, como a hemoglobina (B14), a temperatura corpórea (B15), os valores das gasometrias arterial (B19 a B24) e venosa (C19 a C24), a pressão venosa central (B26), a freqüência cardíaca (B29), a pressão arterial média (B30), o débito cardíaco (C33), a pressão arterial pulmonar média (C34) e a pressão capilar, pulmonar (C35). No total, o intensivista deverá digitar vinte e oito (28) dados. Os parâmetros fisiológicos, normatizados, descritos em detalhe, a seguir, são fornecidos automaticamente. O exemplo fornecido é o de um determinado paciente, jovem, portador de sepse, por trauma abdominal aberto. O exemplo de relatório de exploração hemodinâmica pode ser visaualizado na íntegra na Figura 1. 


\begin{tabular}{|c|c|c|}
\hline \multicolumn{3}{|c|}{ UNIDADE DE EMERGENCIA } \\
\hline \multicolumn{3}{|c|}{ Disciplina de Terapia Intensiva } \\
\hline \multirow{2}{*}{\multicolumn{3}{|c|}{$\begin{array}{c}\text { Departamento de Cirurgia, Ortopedia e Traumatologia } \\
\text { Faculdade de Medicina de Ribeirão Preto - USP }\end{array}$}} \\
\hline & & \\
\hline \multicolumn{3}{|c|}{ Relatório de Monotorização Hemodinâmica (Swan-Ganz) } \\
\hline Paciente $=$ & Idade = & Sexo = \\
\hline \multicolumn{3}{|l|}{ Data $=$} \\
\hline Peso Corpóreo (kg) & 72 & \\
\hline Altura (cm) & 161 & \\
\hline Hemoglobina ( $\mathrm{g} \%)$ & 12,2 & \\
\hline Temperatura (C) & 37,1 & \\
\hline FIO2 & 1 & \\
\hline Gasometria & Arterial & Venosa Central \\
\hline $\mathrm{pH}$ & 7,44 & 7,37 \\
\hline pCO2 $(\mathrm{mmHg})$ & 36 & 45 \\
\hline $\mathrm{pO} 2(\mathrm{mmHg})$ & 172 & 36 \\
\hline $\mathrm{HCO} 3(\mathrm{mM} / \mathrm{L})$ & 26 & 28 \\
\hline TCO2 (mM/L) & 27 & 29 \\
\hline $\mathrm{DB}(\mathrm{mM} / \mathrm{L})$ & 2 & 3 \\
\hline Sat $02(\%)$ & 99 & 70 \\
\hline PVC (cmH2O) & 12 & \\
\hline PVC $(\mathrm{mmHg})=(\mathrm{PVC}$ em cmH2O * 0.735) & 8,82 & \\
\hline Superfície Corpórea (m2) & 1,76 & \\
\hline Freqüência Cardíaca (BPM) & 90 & \\
\hline \multirow[t]{3}{*}{ Pressão Arterial Sistêmica Média $(\mathrm{mmHg})$} & 81 & \\
\hline & Valores & Valores \\
\hline & Normais & Obtidos \\
\hline Débito Cardíaco (L/min) & $4-6$ & 4,5 \\
\hline Pressão Arterial Pulmonar Média (mmHg) & $10-20$ & 26 \\
\hline Pressão Capilar Pulmonar (mmHg) & $<12$ & 12 \\
\hline Pressão Alveolar de Oxigênio (mmHg) & $600-640$ * & 618 \\
\hline Diferença Alvéolo-Arterial de Oxigênio (mmHg) & $<200^{*}$ & 582 \\
\hline Conteúdo de Oxigênio no Sangue Arterial (mL\%) & $17.5-20$ & 17,32 \\
\hline Conteúdo de Oxigênio no Sangue Venoso (mL\%) & $14-16$ & 11,98 \\
\hline Conteúdo de Oxigênio nos Capilares Pulmonares (mL\%) & $18-20$ & 18,87 \\
\hline Oferta de Oxigênio (mL/min/m2) & $520-700$ & 779 \\
\hline Consumo de Oxigênio (mL/min/m2) & $180-300$ & 240 \\
\hline Indice de Extração de Oxigênio (\%) & $20-25$ & 31 \\
\hline Volume Sistólico (mL) & $50-70$ & 50,0 \\
\hline Trabalho Sistólico do Ventrículo Esquerdo (gm.M) & $50-70$ & 46,92 \\
\hline Indice Cardíaco (L/min/m2) & $2.8-4.0$ & 2,56 \\
\hline Indice Sistólico (mL/m2) & $35-50$ & 28,40 \\
\hline Resistência Vascular Sistêmica (din/seg/cm-5) & $770-1500$ & 1283 \\
\hline Resistência Vascular Pulmonar (din/seg/cm-5) & $50-200$ & 249 \\
\hline Shunt Pulmonar (Qs/Qt) (\%) & $5.0-7.0$ & 22,52 \\
\hline${ }^{*}$ Para FIO2 = 1 ( Prova de Hiperóxia durante 15 min. ) & & \\
\hline
\end{tabular}

Figura 1 -Exemplo de relatório de exploração hemodinâmica, baseado no programa Excel 7.0 e implantado pela Disciplina de Terapia Intensiva, na UTI da Unidade de Emergência da Faculdade de Medicina de Ribeirão Preto da Universidade de São Paulo. 


\section{Cálculos dos Parâmetros \\ Fisiológicos Normatizados}

O débito cardíaco é o volume de sangue ejetado pelo coração, por unidade de tempo. Os seus valores normais situam-se entre 4.0 e $6.0 \mathrm{~L} / \mathrm{min}$. Atualmente, a medida do débito cardíaco, por termodiluição computadorizada, através do uso do cateter de Swan-Ganz, tornou-se de fácil execução em Unidades de Terapia Intensiva que dominam as técnicas de monitorização hemodinâmica invasiva e dispõem do equipamento necessário. Normalmente, as medidas obtidas a partir desta monitorização podem ser visualizadas no "display" do computador e, além do débito cardíaco, incluem: a pressão arterial sistêmica média, a pressão arterial pulmonar média, e a pressão capilar pulmonar, ocluída, cujos valores normais são de 60 a 100 $\mathrm{mmHg}, 10$ a $20 \mathrm{mmHg}$ e 10 a $12 \mathrm{mmHg}$, respectivamente. A partir desses dados hemodinâmicos, uma série enorme de cálculos podem ser efetuados, baseados em equações que envolvem constantes fisológicas, definidas há muito tempo.

\section{Pressão Venosa Central}

A medida da pressão venosa central (PVC), utilizada largamente nas Unidades de Terapia Intensiva, é efetuada, classicamente, para avaliar a função do ventrículo direito e sua pressão de enchimento. Em virtude de as pressões do ventrículo direito, normalmente, refletirem também aquelas do ventrículo esquerdo, através da lei dos vasos comunicantes, costuma-se correlacionar as pressões de enchimento das duas câmaras ventriculares. Por esta razão, o estudo da pressão de enchimento da câmara cardíaca, direita, imprescindível nos casos de choque, pode ser realizado de maneira rápida e fácil, através da prova de expansão volêmica, com medida seriada da PVC ${ }^{(2)}$. Contudo, foram constatadas diferenças importantes nessas pressões, sobretudo quando o sistema de vasos comunicantes estava interrompido, como nas grandes insuficiências e/ou estenoses valvulares, na embolia pulmonar e nos aumentos da resistência vascular pulmonar. $\mathrm{O}$ valor normal da PVC situa-se entre 8 e $12 \mathrm{cmH}_{2} \mathrm{O}$, quando o ponto zero é fixado na linha axilar média, com o paciente em decúbito dorsal. $\mathrm{O}$ valor obtido de $\mathrm{PVC}$, em $\mathrm{cmH}_{2} \mathrm{O}$, deve ser digitado na célula B26. Automaticamente, a célula B27 converterá este valor de $\mathrm{cmH}_{2} \mathrm{O}$ em $\mathrm{mmHg}$, na seguinte equação: $\mathbf{B 2 7}=\mathbf{B 2 6} * \mathbf{0 . 7 3 5}$, onde 0.735 é a constante de conversão de $\mathrm{cmH}_{2} \mathrm{O}$ para $\mathrm{mmHg}$.

\section{Superfície Corpórea}

A superfície corpórea (SC), útil para o cálculo do índice cardíaco, é obtida através da equação clássica de Du Bois e Du Bois ${ }^{(3)}$ :

\section{$\mathrm{SC}=$ Peso $(\mathrm{kg})^{0.425} \times$ Altura $(\mathrm{cm})^{0.725} \times 0.007184$}

Assim sendo, o método de cálculo da superfície corpórea (célula A28) será:

$A 28=\left(B 12^{\wedge} 0.425\right)^{\star}\left(B 13^{\wedge} 0.725\right)^{\star}(71.84) / 10000$

\section{3. Índice Cardíaco}

O índice cardíaco (IC) é expresso pelo débito cardíaco (DC em L/min) por unidade de superfície

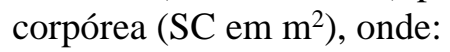

IC $\left(\mathrm{L} / \mathrm{mim} / \mathrm{m}^{2}\right)=\mathrm{DC} / \mathrm{SC}$

O índice cardíaco (célula C46), cujo valor normal situa-se entre 2.8 e $4.0 \mathrm{~L} / \mathrm{min} / \mathrm{m}^{2}$, é calculado da seguinte maneira:

$$
\mathrm{C} 46=(\mathrm{C} 33 / \mathrm{B} 28)
$$

\section{Pressão Alveolar de Oxigênio}

$\mathrm{O}$ ar alveolar é o resultado da mistura do ar inspirado com o ar pré-existente nos alvéolos. A difusão do gás alveolar para os capilares pulmonares depende da concentração fracionária ou pressão parcial de todos os gases alveolares, exceto do oxigênio. $\mathrm{O}$ valor da pressão alveolar de oxigênio $\left(\mathrm{P}_{\mathrm{A}} \mathrm{O}_{2}\right)$, cujo valor normal situa-se entre 600 e $640 \mathrm{mmHg}$, pode ser estimada através da seguinte equação:

$$
\mathrm{P}_{\mathrm{A}} \mathrm{O}_{2}=\left(\mathrm{Pb}-\mathrm{PH}_{2} \mathrm{O}\right) \times \mathrm{F}_{1} \mathrm{O}_{2}-\mathrm{PaCO}_{2} / 0.8
$$

onde:

$\mathbf{P b}=$ Pressão barométrica $=710 \mathrm{mmHg}$ (região de Ribeirão Preto, SP);

$\mathbf{P H}_{2} \mathbf{O}=$ Pressão parcial de vapor de água no alvéolo $=47 \mathrm{mmHg}$;

$\mathbf{F}_{\mathbf{I}} \mathbf{O}_{2}=$ Fração de oxigênio no ar inspirado $=$ $100 \%$ ou 1 minutos);

(para prova de hiperóxia, durante quinze (15)

$\mathbf{P a C O}_{2}=$ Pressão parcial de $\mathrm{CO}_{2}$ no sangue arterial, em $\mathrm{mmHg}$.

Dessa maneira, o cálculo da $\mathrm{P}_{\mathrm{A}} \mathrm{O}_{2}$, no presente exemplo (Figura 1), é o seguinte:

$$
\mathrm{P}_{\mathrm{A}} \mathrm{O}_{2}=(\mathbf{7 1 0}-\mathbf{4 7}) \times 1-36 / 0.8=618 \mathrm{mmHg} .
$$

A representação no relatório de exploração hemodinâmica da $\mathrm{P}_{\mathrm{A}} \mathrm{O}_{2}$ (célula $\mathrm{C} 36$ ) é:

$$
\left.\mathrm{C} 36=\left((710-47)^{\star} 1\right)-(B 19 / 0.8)\right)
$$




\section{Diferença Alvéolo-Arterial de Oxigênio}

A diferença ou gradiente alvéolo-arterial de oxigênio - $\mathrm{D}(\mathrm{A}-\mathrm{a}) \mathrm{O}_{2}$ constitui, na prática diária, o método mais simples de quantificar a disfunção pulmonar, no paciente crítico, sobretudo nos casos de SARA (Síndrome de Angústia Respiratória do Adulto). Ao lado do "shunt" pulmonar, a $\mathrm{D}(\mathrm{A}-\mathrm{a}) \mathrm{O}_{2}$ contribui para o estudo das desigualdades de ventilação/ perfusão do pulmão e da admissão do sangue venoso no sangue arterial.

$\mathrm{O}$ valor da $\mathrm{D}(\mathrm{A}-\mathrm{a}) \mathrm{O}_{2}$, que geralmente é menor do que $200 \mathrm{mmHg}$ (para $\mathrm{F}_{\mathrm{I}} \mathrm{O}_{2}=1$ ), pode ser estimado através da seguinte equação:

$\mathrm{D}(\mathrm{A}-\mathrm{a}) \mathrm{O}_{2}=\mathrm{P}_{\mathrm{A}} \mathrm{O}_{2}-\mathrm{PaO}_{2}$ onde:

$\mathbf{P a O}_{2}=$ Pressão parcial de $\mathrm{O}_{2}$ no sangue arterial, em $\mathrm{mmHg}$.

Assim sendo, a equação final será:

$$
\mathrm{D}(\mathrm{A}-\mathrm{a}) \mathrm{O}_{2}=\left(\mathrm{Pb}-\mathrm{PH}_{2} \mathrm{O}\right) \times \mathrm{F}_{1} \mathrm{O}_{2}-\mathrm{PaCO}_{2} / 0.8-\mathrm{PaO}_{2}
$$

Efetua-se o seu cálculo (célula C37) da seguinte maneira:

$$
\mathrm{C} 37=(\mathrm{C} 36-\mathrm{C} 20)
$$

\section{Conteúdo de Oxigênio no Sangue Arterial, Ve- noso e dos Capilares Pulmonares}

Para o cálculo do "shunt" pulmonar e da oferta de oxigênio, normalmente afetados no choque e no hipermetabolismo, é necessário determinar, inicialmente, o conteúdo de $\mathrm{O}_{2}\left(\mathrm{CaO}_{2}\right)$ no sangue arterial, no sangue venoso misto $\left(\mathrm{CvO}_{2}\right)$ e nos capilares pulmonares $\left(\mathrm{Cc}^{\prime} \mathrm{O}_{2}\right)$. Estes são calculados a partir das respectivas pressões parciais nos sangues arterial e venoso de $\mathrm{O}_{2}\left(\mathrm{PO}_{2}\right.$, em mmHg$)$, saturações de $\mathrm{O}_{2}\left(\mathrm{SO}_{2}\right)$ e da concentração sérica de hemoglobina $(\mathrm{g} \%)$. Para o cálculo do conteúdo de $\mathrm{O}_{2}$ nos capilares pulmonares, a pressão parcial de $\mathrm{O}_{2}$ local é considerada igual à $\mathrm{P}_{\mathrm{A}} \mathrm{O}_{2}$ e a saturação de $\mathrm{O}_{2}$ é igual a 1 , no caso de o paciente estar com um a $\mathrm{F}_{\mathrm{I}} \mathrm{O}_{2}>0.4{ }^{(4)}$. Dessa maneira, o cálculo do $\mathrm{CaO}_{2}$ e do $\mathrm{Cc}^{\prime} \mathrm{O}_{2}$ serão os seguintes:

$$
\begin{aligned}
\mathrm{CaO}_{2}= & \left(\mathbf{1 . 3 9} \times \mathbf{H b} \times \mathbf{S a O}_{2}\right)+\left(\mathbf{0 . 0 0 3 1} \times \mathbf{P a O}_{2}\right) . \\
& \text { (Valor normal: } 17.5-20 \mathrm{~mL} \%)
\end{aligned}
$$

A representação da $\mathrm{CaO}_{2}$, no relatório de exploração hemodinâmina será:

\section{$C 38=\left(1.39^{\star} B 14^{\star}(B 24 / 100)+\left(0.0031^{\star} B 20\right)\right)$}

\section{$\mathrm{CvO}_{2}=\left(\left(1.39 \times \mathrm{Hb} \times \mathrm{SvO}_{2}\right)+\left(0.0031 \times \mathrm{PvO}_{2}\right)\right)$. \\ (Valor normal: $14-16 \mathrm{~mL} \%$ )}

A representação da $\mathrm{CaO}_{2}$, no relatório de exploração hemodinâmina, será:

\section{$\mathrm{C} 39=\left(1.39^{\star} \mathrm{B} 14^{\star}(\mathrm{C} 24 / 100)+\left(0.0031^{*} \mathrm{C} 20\right)\right)$}

$$
\mathrm{Cc}^{\prime} \mathrm{O}_{2}=(1.39 \times \mathrm{Hb})+\left(0.0031 \times \mathrm{P}_{\mathrm{A}} \mathrm{O}_{2}\right) \text {. }
$$

(Valor normal: $18-20 \mathrm{~mL} \%$ )

A representação da $\mathrm{Cc}^{\prime} \mathrm{O}_{2}$, no relatório de exploração hemodinâmina, será:

$$
C 40=(1.39 * B 14)+\left(0.0031^{\star} \mathrm{C} 36\right)
$$

\section{Shunt Pulmonar}

O "shunt" pulmonar (Qs/Qt: Valor normal $5-7 \%$ ) é o guia mais utilizado para avaliar o grau de disfunção pulmonar ou de admissão do sangue venoso no sangue arterial, resultado do comprometimento dos capilares pulmonares ou de alvéolos não funcionantes que é, geralmente, observado na síndrome do choque circulatório, mais notadamente o séptico, e a SARA. Assim, o método mais correto para o cálculo do "shunt" pulmonar é o da colheita de sangue arterial na artéria radial e de sangue venoso na artéria pulmonar, através do cateter de Swan-Ganz, após uma prova de hiperoxia $\left(\mathrm{F}_{\mathrm{I}} \mathrm{O}_{2}=1\right.$, durante quinze (15) minutos). O cálculo do "shunt" pulmonar emprega os conteúdos de $\mathrm{O}_{2}$, no sangue arterial, venoso e dos capilares pulmonares.

$$
\frac{\mathrm{Qs}}{\overline{\mathrm{Qt}}} \frac{\mathrm{Cc}^{\prime} \mathrm{O}_{2}-\mathrm{CaO}_{2}}{\mathrm{Cc}^{\prime} \mathrm{O}_{2}-\mathrm{CvO}_{2}}
$$

$$
\frac{Q s}{Q t} \frac{(1.39 \times \mathrm{Hb})+\left(0.0031 \times \mathrm{P}_{\mathrm{A}} \mathrm{O}_{2}\right)-\left(1.39 \times \mathrm{Hb} \times \mathrm{SaO}_{2}\right)+\left(0.0031 \times \mathrm{PaO}_{2}\right)}{(1.39 \times \mathrm{Hb})+\left(0.0031 \times \mathrm{P}_{\mathrm{A}} \mathrm{O}_{2}\right)-\left(1.39 \times \mathrm{Hb} \times \mathrm{SvO}_{2}\right)+\left(0.0031 \times \mathrm{PvO}_{2}\right)}
$$

A expressão do cálculo matemático do "shunt" pulmonar, no relatório final, será:

$$
\mathrm{C} 50=(\mathrm{C} 40-\mathrm{C} 38) /(\mathrm{C} 40-\mathrm{C} 39)^{\star} 100
$$

\section{Oferta de Oxigênio}

A oferta de oxigênio $\left(\mathrm{DO}_{2}\right)$ é de crucial importância na manutenção da respiração celular e nos 
processos metabólicos oxidativos. Sob a luz da fisiologia, aproximadamente $25 \%$ do conteúdo arterial de $\mathrm{O}_{2}$ é extraído pelos tecidos a cada minuto (Valor normal da $\mathrm{DO}_{2}$ : 520 a $700 \mathrm{~mL} / \mathrm{min} / \mathrm{m}^{2}$ ). Porém, esta extração pode elevar-se a $80 \%$ em situações de hipermetabolismo, como a sepse, ou de baixa perfusão periférica, como a síndrome do choque de qualquer etiologia. Se houver um decréscimo crítico, abaixo de $300 \mathrm{~mL} / \mathrm{min} / \mathrm{m}^{2}$, na oferta de $\mathrm{O}_{2}$, a extração aumentada não será suficiente para suprir as necessidades teciduais metabólicas ${ }^{(5)}$. O método empregado para o cálculo da $\mathrm{DO}_{2}$ (célula C41) é o seguinte:

$$
\mathrm{DO}_{2}\left(\mathrm{~mL} / \mathrm{min} / \mathrm{m}^{2}\right)=\mathrm{DC} \times \mathrm{CaO}_{2} \times 10
$$

onde: $\mathrm{DC}=$ Débito cardíaco $(\mathrm{L} / \mathrm{min})$;

$\mathrm{CaO}_{2}=$ Conteúdo de $\mathrm{O}_{2}$ no sangue arterial $(\mathrm{mL} \%)$.

A expressão do cálculo matemático da oferta de oxigênio, no relatório final, será:

\section{$\mathrm{C} 41=\mathrm{C} 33^{*} \mathrm{C} 38^{*} 10$}

\section{Consumo de Oxigênio}

$\mathrm{O}$ consumo de oxigênio $\left(\mathrm{VO}_{2}\right)$ indica a quantidade de $\mathrm{O}_{2}$, utilizada pelos tecidos e é determinado, em condições fisiológicas normais, pelas necessidades metabólicas individuais de cada tecido orgânico, normalmente independente da oferta de oxigênio. A taxa de consumo de oxigênio é uma medida global do metabolismo corpóreo, representando a somatória de todas as reações oxidativas celulares. $\mathrm{O} \mathrm{VO}_{2}$ é o produto do débito cardíaco (DC) pela diferença arteriovenosa dos conteúdos de $\mathrm{O}_{2}\left(\mathrm{CaO}_{2}-\mathrm{CvO}_{2}\right)$. O seu valor normal gira em torno de 180 a $300 \mathrm{ml} / \mathrm{min} / \mathrm{m}^{2} \mathrm{e}$ é definido pela seguinte equação:

\section{$\mathrm{VO}_{2}\left(\mathrm{~mL} / \mathrm{min} / \mathrm{m}^{2}\right)=\left(\mathrm{DC}(\mathrm{L} / \mathrm{min}) \times\left(\mathrm{CaO}_{2}-\mathrm{CvO}_{2}\right)\right) * 10$}

A representação esquemática no programa Excel 7.0 será:

\section{$\mathrm{C} 42=\left(\mathrm{C} 33^{*}(\mathrm{C} 38-\mathrm{C} 39)^{*} 10\right)$}

\section{0. Índice de Extração de Oxigênio}

Conforme foi mencionado anteriormente, o índice de extração de oxigênio (IEO) reflete a porcentagem de extração de $\mathrm{O}_{2}$ em relação à oferta, indicando a fração de $\mathrm{O}_{2}$, extraída do conteúdo de $\mathrm{O}_{2}$ arterial, durante sua passagem pelos diversos tecidos orgânicos. O seu valor normal situa-se entre 20 e $25 \%$ e é definido pela equação matemática abaixo:

$$
\operatorname{IEO}(\%)=\left(\left(\mathrm{CaO}_{2}-\mathrm{CvO}_{2}\right) / \mathrm{CaO}_{2}\right) * 100,
$$

onde no relatório final aparecerá como:

$$
\mathrm{C} 43=((\mathrm{C} 38-\mathrm{C} 39) / \mathrm{C} 38)^{\star} 100
$$

\section{Volume Sistólico}

O volume sistólico (VS) compreende o volume de sangue, em mililitros, ejetado por cada sístole do ventrículo esquerdo para a aorta. O seu valor normal situa-se entre 50 a $70 \mathrm{ml}$ e pode estar comprometido nos casos de depressão miocárdica por toxinas ou pela falência muscular. O VS é calculado pela simples relação entre o débito cardíaco (DC) e a frequiência cardíaca (FC):

$$
\text { VS }(m L)=(D C / F C) * 1000,
$$

sendo representado no relatório como:

\section{$\mathrm{C} 44=(\mathrm{C} 33 / \mathrm{B} 29)^{*} 1000$}

\section{Trabalho Sistólico do Ventrículo Esquerdo}

O trabalho sistólico do ventrículo esquerdo (TSVE) é simplesmente o produto do volume sistólico (VS) pela diferença entre a pressão arterial sistêmica média (PAM) e a pressão capilar pulmonar (PCP), que corresponde à pressão diastólica, final, do ventrículo esquerdo. O valor normal do TSVE é de 50 a 70 gm.M. O seu cálculo efetua-se da seguinte maneira:

\section{TSVE (gm.M) $=$ VS * $(P A M-P C P)$ * 0.0136,}

onde esquematicamente será:

$$
\mathrm{C} 45=\mathrm{C}_{4}{ }^{\star}(\mathrm{B} 30-\mathrm{C} 35)^{\star} 0.0136
$$

\section{3. Índice Sistólico}

O índice sistólico (IS) avalia a simples relação entre índice cardíaco (IC) e a freqüência cardíaca (FC). O IS indica o volume de ejeção do ventrículo esquerdo em relação à superfície corpórea do paciente. O seu valor normal está entre 35 e $50 \mathrm{~mL} / \mathrm{m}^{2}$ e é expresso da seguinte maneira:

$$
\text { IS }\left(\mathrm{mL} / \mathrm{m}^{2}\right)=(\mathrm{IC} / \mathrm{FC}) * 1000,
$$

onde a representação no relatório será:

$$
\text { C47 }=(C 33 / B 28) * 1000
$$

\section{m. Resistência Vascular Sistêmica}

A resistência vascular sistêmica (RVS: Valor normal de 770 a $1500 \mathrm{din} / \mathrm{seg} / \mathrm{cm}^{-5}$ ) é o resultado da subtração da pressão arterial sistêmica média (PAM) 
pela pressão venosa central (PVC) dividido pelo débito cardíaco (DC). O seu cálculo é efetuado da maneira exposta abaixo:

\section{RVS $=((P A M-(P V C * 0.735)) /(D C * 1000)) * 79980$,} onde:

\section{$C 48=\left(\left(B 30-\left(B 26^{\star} 0.735\right)\right) /\left(C 33^{\star} 1000\right)\right)^{\star} 79980$}

\section{Resistência Vascular Pulmonar}

A resistência vascular pulmonar (RVP: Valor normal de 50 a $200 \mathrm{din} / \mathrm{seg} / \mathrm{cm}^{-5}$ ) é calculada pela subtração da pressão média da artéria pulmonar (PAPM) pela pressão capilar pulmonar (PCP), dividida pelo débito cardíaco (DC), conforme a seguinte equação:

$$
\text { RVP = ((PAPM - PCP) / (DC * 1000) }{ }^{*} 79980
$$

onde:

$$
\mathrm{C} 49=\left((\mathrm{C} 34-\mathrm{C} 35) /\left(\mathrm{C}_{3}{ }^{\star} 1000\right)\right)^{\star} 79980
$$

Embora existam outros métodos informatizados para os cálculos dos parâmetros hemodinâmicos ${ }^{(6)}$, a partir das informações originadas pelo Swan-Ganz, nos parece que o uso de um software de uso corriqueiro, como o Excel 7.0, torna estes cálculos muito mais fáceis e acessíveis a qualquer Intensivista ou Unidade de Terapia Intensiva.

Algumas considerações finais devem ser tecidas em relação ao uso do cateter de Swan-Ganz, utilizado no intuito de explorar, de maneira invasiva, as variáveis envolvidas no controle hemodinâmico de um determinado paciente grave. No entanto, o intensivista deve ter em mente, por tratar-se de procedimento invasivo, dos riscos mecânicos e infecciosos, inerentes ao cateterismo da artéria pulmonar ${ }^{(7,8)}$. É sempre bom lembrar que este tipo de monitorização é uma técnica que auxilia no diagnóstico das perturbações hemodinâmica e metabólicas, não representando, de forma alguma, uma modalidade terapêutica ${ }^{(9,10)}$.

\section{REFERÊNCIAS BIBLIOGRÁFICAS}

1 - SWAN HJC; GANZ N \& FORRESTER JS. Catheterization of the heart in man with one of a flow-directed ballow-tipped catheter. N Engl J Med 283: 447-451, 1970.

2 - BASILE FILHO A et al. A prova de expansão volêmica, através da pressão venosa central, pode ser utilizada para racionalizar os custos e o uso de drogas vasoativas nos pacientes graves?. Arq Bras Med 69: 77-79, 1995.

3 - Du BOIS D \& DuBOIS EF. A formula to estimate the approximate surface area if height and weight are known. Arch Intern Med 17: 863-871, 1916.

4 - SIEGEL JH; GIOVANNINI I \& COLEMAN B. Ventilation/perfusion maldistribution secondary to the hyperdynamic cardiovascular state as the major cause of increased pulmonary shunting in human sepsis. J Trauma 19: 432-460, 1979.

5 - SCHWARTZ S; FRANTZ RA \& SHOEMAKER WC. Sequential hemodynamic and $\mathrm{O}_{2}$ transport response to hypovolemia, anemia and hypoxia. Am J Physiol 241:864-871, 1981.

6 - TERZI RGG. Aplicativos para a avaliação do equilíbrio ácido-básico e transporte de oxigênio. In: TERZI RGG. Equilíbrio ácido-básico e transporte de oxigênio. São Paulo, Manole, p. 221, 1992.

7 - DIAS FS. Vinte anos de "Swan-Ganz". Arq Bras Cardiol 56:435-443, 1991.

8 - PATEL C; LABOY V \& VENUS B. Acute complications of pulmonary artery catheter insertion in critically ill patients. Crit Care Med 14: 195-197, 1986.

9 - CHATTERJEE K; MATHAY MA. Right heart catheterization is a diagnostic procedure, not a therapeutic intervention (Editorial). J Intensive Care Med 6: 101, 1991.

10 - ROBIN EG. The cult of the Swan-Ganz catheter overuse and abuse of pulmonary flow catheters. Ann Intern Med 103: 445-449, 1985. 